\title{
Asthma and climatic conditions: experience from Bermuda, an isolated island community
}

\author{
M J CAREY, I CORDON
}

\begin{abstract}
A retrospective study of patients attending the emergency department with acute asthma was performed in Bermuda. Climatic data (barometric pressure, rainfall, humidity, and wind strength and direction) were obtained and compared with frequency of exacerbations of asthma. Three factors-namely, relative humidity, average daily temperature, and northeasterly winds - were found to be related to worsening asthma.

Owing to Bermuda's lack of pollution and aeroallergens it was thought that these weather parameters had a direct effect on the asthmatic population.
\end{abstract}

\section{Introduction}

In Bermuda it has long been thought that an easterly wind triggers asthmatic episodes; both general practitioners and their patients believe this to be true.

Bermuda, a small, isolated island, is almost completely free of atmospheric pollution and has exceptionally low pollen counts year round. Thus it is an ideal location to investigate the relation between asthmatic episodes and climatic conditions. In addition, as there is only one facility for treating acute asthma, all episodes of acute asthma could reasonably be expected to be identified during the period of study.

\section{Method}

Bermuda is a fish hook shaped island about 21 miles $(34 \mathrm{~km})$ long and 1 mile $(1.6 \mathrm{~km})$ wide. It is situated 32 degrees 22 minutes north, 64 degrees 41 minutes west, or 670 miles $(1070 \mathrm{~km})$ east south east of New York. It enjoys a subtropical climate, with extremes of mean daily temperature of $27^{\circ} \mathrm{C}$ in

King Edward VII Memorial Hospital, Paget, Bermuda

$M$ J CAREY, $M B, B C H$, resident medical officer

I CORDON, MB, $\operatorname{FRCP}(\mathrm{C})$, director, emergency medicine

Correspondence to: Dr I Cordon, Emergency Department, King Edward VII Memorial Hospital, PO Box HM 1023, Hamilton 5, Bermuda.
August and $16^{\circ} \mathrm{C}$ in February. Rain falls equally throughout the year and humidity is generally high.

The King Edward VII Memorial Hospital is the only general hospital in Bermuda. The emergency department treats about 26000 patients a year. About 900 of these visits are for acute asthmatic episodes. These patients are drawn from a population of roughly 55000 . Tourists ( 530000 a year) were excluded from the study.

Data were obtained from the attendance record book for the emergency department for 1983 and 1984 . This $\log$ records details of all patients seen as emergencies. All patients with a diagnosis of asthma, but excluding cardiac asthma, were included in the study.

Daily climatic data (barometric pressure, rainfall, relative humidity, average temperature, and wind strength and direction) for 1983 and 1984 were obtained from the United States Naval Oceanography Command Facility, Bermuda. On days when one particular wind direction predominated this was the direction recorded; otherwise a mean direction was calculated.

Detailed statistical analysis of all results was performed by the Government of Bermuda department of statistics using $\chi^{2}$ analyses.

\section{Results}

Between 1 January 1983 and 31 December 1984, 1749 patients visited the hospital's emergency department with a diagnosis of exacerbation of asthma. Of these, $262(15 \%)$ required inpatient care.

There was no significant relation between daily attendances with asthma and barometric pressure, rainfall, or wind strength. Attendances did, however, vary with both relative humidity and average air temperature (tables I and II). The lower the relative humidity the greater was the number of asthmatics seen in the emergency department $(p<0.01)$, and the lower the air temperature the greater the average daily number of asthmatics seen $(\mathbf{p}<0.01)$.

Table III shows that when the wind was from the north (especially the north east) the average number of patients with asthma seen daily in the emergency room was significantly greater than expected by chance

TABLE I-Average numbers of patients seen daily and relative humidity

\begin{tabular}{lcccccc}
\hline & \multicolumn{6}{c}{ Daily relative humidity $(\%)$} \\
\cline { 2 - 7 } & $\leqslant 50$ & $51-$ & $61-$ & $71-$ & $81-$ & $\geqslant 91$ \\
\hline Average No of patients daily & 3.7 & 3.1 & 2.8 & 2.4 & 2.0 & 2.2
\end{tabular}


TABLE II-Average numbers of patients seen daily and average daily temperatures

\begin{tabular}{lcccc}
\hline & \multicolumn{4}{c}{ Average daily temperature $\left({ }^{\circ} \mathrm{C}\right)$} \\
\cline { 2 - 6 } & $11-$ & $16-$ & $21-$ & $\geqslant 26$ \\
\hline Average No of patients daily & 3.0 & $2 \cdot 7$ & 2.5 & $1 \cdot 7$
\end{tabular}

TABLE III-Effect of wind direction on average daily attendances for asthma

\begin{tabular}{lccccccccc}
\hline & \multicolumn{1}{c}{ Wind direction } \\
\cline { 2 - 9 } & N & NE & E & SE & S & SW & W & NW \\
\hline Average No of patients daily & 2.5 & 3.3 & 2.0 & $2 \cdot 2$ & 2.0 & 2.0 & 2.4 & $2 \cdot 7$ \\
\hline
\end{tabular}

TABLE IV-Relation of temperature and relative humidity to wind direction

\begin{tabular}{lcc}
\hline Wind direction & Relative humidity $(\%)$ & Temperature $\left({ }^{\circ} \mathrm{C}\right)$ \\
\hline Southwesterly (178 days) & $78 \cdot 9$ & $23 \cdot 5$ \\
Northeasterly (88 days) & $72 \cdot 2$ & $21 \cdot 6$ \\
Annual average & $72 \cdot 6$ & $22 \cdot 0$ \\
\hline
\end{tabular}

$(p<0.01)$. By contrast, when the wind was from the south west significantly fewer asthmatic patients attended.

The daily number of visits to the emergency department with asthma approximately followed a Poisson distribution curve with a mean of 2.4 visits a day. For 1983 and 1984 there was a total of 21 days when seven or more patients attended with acute asthmatic episodes - that is, three times our average daily attendance or more. These so called "epidemic days" have been described in other studies ${ }^{1.4}$ and related to severe thunderstorms and also to the passage of cold fronts. There was no consistent climatic factor associated with the epidemic days in this study.

The appendix shows the results of statistical analysis of our data.

\section{Discussion}

It has long been recognised that cold, dry conditions seem to trigger asthma; the paediatrician Lionel Chambers made this observation in 1776. Strauss et al investigated the effect of cold air on asthma. ${ }^{5}$ They found a $100 \%$ drop in forced expiratory volume in one second when asthmatic patients breathed air at $-13^{\circ} \mathrm{C}$ compared with breathing air at $24^{\circ} \mathrm{C}$. In Bermuda such very low temperatures do not occur (the lowest recorded temperature is $6^{\circ} \mathrm{C}$ ), but the bronchospasm producing effect of cool air seems to be consistent in producing a linear relation between falling temperature and increasing frequency of attendances for asthma.

The asthma epidemics in New Orleans were associated with the passage of a cold front and a concurrent drop in humidity. ${ }^{2}$ It was thought that high humidity tended to "cleanse" the air of pollutants. Asthma epidemics in Birmingham, United Kingdom, in $1983^{4}$ and Melbourne in $1984^{6}$ were associated with thunderstorms and dramatic rises in humidity. The suggested mechanism in these cases was pollen of short ragweed forming an antigen rich aerosol on contact with moisture which induced the bronchospasm. Another suggestion was that the increased humidity triggered a massive release of fungal spores, notably of Didymella exitialis, which is dependent on moisture for spore release. In Bermuda Dewdeney $e t$ al showed the main allergen responsible for allergic respiratory disease to be derived from the house dust mite Dermatophagoides pteronyssinus. ${ }^{7}$ Neither ragweed nor plantain pollen is present in significant numbers, if at all. Various fungal moulds do grow in Bermuda but skin testing atopic subjects yielded positive reactions in only $10 \%$ (compared with $73 \%$ for $D$ pteronyssinus).

Table IV shows that humidity and temperature with a north east wind are very close to the annual average. By comparison, the south west wind, which seems very beneficial for asthmatics, brings higher humidity and higher temperatures. The asthma provoking quality of a northeasterly wind seems therefore independent of the effects of low temperature and humidity. This supports the observation of many Bermudian asthmatics and their doctors that a specific wind direction produces exacerbations of asthma. A north wind (especially northeasterly) is the wind responsible, not the east wind as previously believed. It is unlikely that the north east wind brings appreciable quantities of aeroallergens as there is nothing to the north east of Bermuda but several thousand miles of ocean.

We thank G K Stanton for the statistical analysis, and Kirsten Luckhurst for help in preparing the manuscript.

\section{Appendix}

RESULTS OF STATISTICAL ANALYSIS

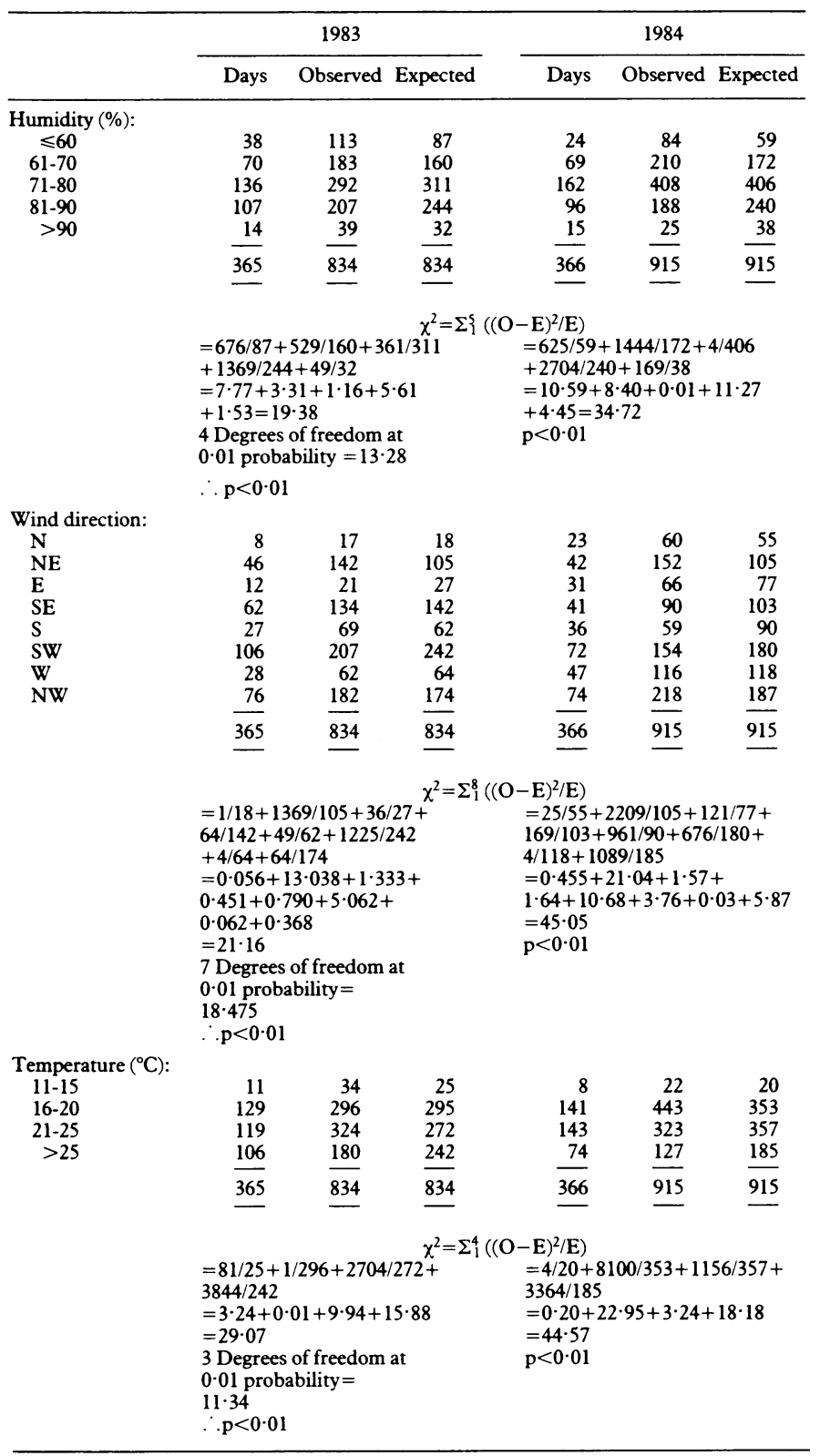

\section{References}

1 Anonymous. Asthma and the weather [Editorial]. Lancet 1985; ;: 1079-80.

2 Goldstein IF. Weather patterns and asthma epidemics in New York City and New Orleans, USA Int 7 Biometeorol 1980;24:329-39.

Brown HMelool 198,24:329-39.

4 Packe GE, Archer PStJ, Ayres JG. Asthma and the weather. Lancet 1983;ii:281.

5 Strauss RH, McFadden ER, Ingram RH, Jaeger JJ. Enhancement of exercise-induced asthma by cold air. N Engl f Med 1977;297:743-7.

6 Egan P. Weat

7 Dewdeney JM, Hinks D, Manuel E, Shaw CD, Tees EC. A clinical and environmental study of the aeroallergena of the islands of Bermuda. Clin Allergy 1978;8:445-53.

(Accepted 16 fuly 1986) 